\title{
AC 2007-914: THE CHALLENGE OF TEACHING LARGE FIRST YEAR ENGINEERING CLASSES
}

Peter Burton, Royal Melbourne Institute of Technology 


\section{The Challenge of Teaching Large First Year Engineering Classes}

\section{Introduction}

Teaching is not always appreciated to the same extent as research within university environments and yet teaching, particularly of large classes, is a significant source of revenue for universities and a significant contributor to reputation. Academic staff with lecturing responsibilities will often prefer to focus their teaching on fourth year or postgraduate students, because more prestige is associated with these advanced students and classes are generally much smaller, reducing the lecturer's work load. Yet if a university does not have lecturers willing and able to do an excellent job of teaching first year students, retention becomes an issue, as does reputation and consequently recruitment in subsequent years. Recruitment and retention are very important for all universities but are issues that Australian universities are particularly focused on as they move into a period of increased competition, driven by a significant reduction in government funding over recent years and consequently a much higher reliance on student fees and other external income.

Teaching of first year students is particularly important because it is during this critical freshman year that students are most likely to drop out of the system if they become disengaged with the learning process. It is the responsibility and challenge of the first year lecturer not only to teach them the subject matter but also to motivate students, to instill in them a love of the subject, to confirm in the students' minds that the choice they made is the right one, to provide opportunities to cement their learning and also to ensure, at every step of the way, that students are assisted to make the transition from secondary to tertiary studies.

Freshmen and sophomore engineering classes at RMIT University have traditionally been very large, due to the existence of a common first and second year for a total of six programs. Enrollment in a single class has been as high as 300 students but more recently first year classes in the School of Electrical and Computer Engineering have been approximately $150 / 170$ students, the downturn being due to cyclical changes linked to employment opportunities and other external factors. Whether 150 or 300 however, classes of this size present a considerable logistical challenge, as well as a number of other challenges and overcoming these and turning them to advantage should be a key element in the first year lecturer's approach to teaching. Over the course of a number of years experience with freshmen classes, the author has found that there are seven key elements involved in retaining students and educating them for success and consequently in recruiting new students into the program. These elements are an interactive teaching style regardless of class size, regular tutorial groups, voluntary "help" sessions, regular in-class quizzes, regular homework which is marked and returned, the availability of practically focused learning opportunities and the development and availability of quasi-interactive videos.

While all of the above elements have been found to be a significant contributor to success, the availability of practically focused learning opportunities and the impact of quasi interactive videos as a teaching and learning tool are emerging as probably the two most important factors impacting the experience of large segments of the student population and are consequently given most focus in this paper. 


\section{An Interactive Teaching Style}

Walking about the lecture theatre, posing questions to the students, engaging them in the subject matter, encouraging their questions and answering them is, in the author's experience, an integral part of successful freshmen lectures, although this undoubtedly places more demands on the lecturer. In an article entitled 'Large Classes versus Small: Does it make a Difference?' the Schreyer Institute for Teaching Excellence at Penn State University indicates that creating a small class atmosphere in a large class setting is critical for success and that this is in part fostered by the lecturer moving about the lecture theatre or classroom

Although PowerPoint slides are very popular and a very valuable teaching aid in many situations, experience has shown that use of a variety of media has greater potential to retain students' interest and attention and this approach, in conjunction with the use of a white board when discussing problems, enables students to be engaged in the process of finding the correct solution - it facilitates the opportunity to think the issues through together and focuses the students' minds at the tip of the white board marker.

When visiting RMIT University a few years ago Dr Edward DeBono was asked why his lecture aids were not more sophisticated and his response was that 'your mind is at the tip of my pen.' The approach is not high tech but never the less can engage the audience and certainly appears more spontaneous.

Dr. Rabiul Islam in his 2001 paper "Reflections on large class teaching in the social sciences" ${ }^{2}$ talks about the need for students to be active, as opposed to passive learners, and the need for large classes to be interesting. An interactive teaching style helps significantly to achieve this.

\section{The Importance and Role of Tutorial Groups}

Tutorial groups are an essential follow-on from lectures and a valuable opportunity for students to get extra assistance in a small group environment after first attending the lecture. They are often opportunities, particularly in respect of large first year classes, for students to pose questions that they might not want to ask in a large group, to go over material covered in the lecture in more depth and to benefit from each other's issues and questions.

Tutorials also promote discussion and enable students to engage in active problem solving, activities sighted by Light, 1999 as ingredients that help to make large classes work. ${ }^{3}$

It is particularly important in the freshmen year that there is strong continuity between the lecture and the tutorials and that all tutorials associated with a particular class are run in a similar way, provide the same information and examples, and allow the same opportunities for questions. It is preferable for these reasons that all of the tutorials are run by the lecturer, or at least the same teaching assistant, but unfortunately this is not always practical or possible. However, every effort is made to encourage this in the School of Electronic and Computer Engineering at RMIT.

\section{Voluntary Help Sessions}

Even with tutorials and other resources available to students, the offer of non-timetabled additional "help" sessions are an integral and much appreciated addition to some courses at RMIT University, particularly as exam time approaches. Such sessions provide students with 
extra help, extra practice questions and the opportunity to share common problems and study ideas. They are usually offered in the evenings to allow maximum students to attend and results have shown consistently over time that those students who attend help sessions achieve very good exam results. It is not necessarily true to say that the exam results of students who attend the sessions are consistently better than their peers who do not take advantage of this additional resource, since it is normally the weaker or students who are struggling who are most likely to attend. It is true to say though, although very hard to substantiate, that students who attend the extra sessions achieve much better results than would otherwise be expected and this is reflected in the spread of exam results across classes where extra "help" sessions are offered.

\section{Regular In Class Quizzes}

Students have advance notice and therefore an opportunity to prepare for in-class quizzes, which are conducted several times per semester and provide an opportunity for instant feedback, which the author has found to be critically important for students, particularly in first year. Quizzes consist of short questions; they are graded and the result forms part of the overall assessment for that semester.

\section{Homework}

Setting regular homework that is graded and returned provides another opportunity for providing valuable feedback to students. It means that students have to go home and contemplate the lecture and tutorials further in order to get a good grade for the homework and this assists in recall and retention of the information. Simply setting homework assignments but not marking them is insufficient. Many lecturers expect that the keen student will do the work and self correct but this does not provide sufficient incentive for many students and although in years gone by, universities could afford to take the attitude that if students want to pursue higher education they must take responsibility for their own learning, the strong competition between institutions that exists under the current Australian funding model dictates a different approach. It is very important to recruit and attract every capable student who is interested in a particular program and then to go the extra mile to retain them.

\section{Practically Focused Learning Opportunities}

RMIT University prides itself on offering practically focused programs and producing work ready graduates. This is part of the history and tradition of RMIT and is certainly reflected in the programs delivered within the School of Electrical and Computer Engineering.

The strong focus on real world problems and practical applications throughout the program not only has the significant benefit of producing work ready graduates who are immediately of value to an employer, but also has the benefit of maintaining students' interest because they can see a clear connection between what they are learning and where that knowledge can be applied. It enables first year engineering students to see the road ahead and helps to focus them on that road.

Laboratory sessions, run in conjunction with lectures, focus on real world projects and problems and enable first year students to make an immediate connection between theory and practice. Choosing projects that provide students with a real life application, a real challenge but an achievable goal is part of the challenge of teaching first year engineering students. Such 
projects have included the design of traffic light controllers, alarm systems, watering systems and automatic doors.

\section{Quasi Interactive Videos}

The use of quasi interactive video material has become a key element in the author's teaching approach because of the effectiveness of this as a teaching tool, particularly for large first year classes. Consequently, this has been the subject of two previous conference papers and is given considerable focus in this paper. ${ }^{4}$ and 5

Quasi interactive video material is offered as an addition to and not instead of regular lecture classes and takes its name from the fact that lectures are not merely filmed but the videos are scripted, filmed and produced in a manner that makes the student feel that he or she is actively engaging with the presenter.

The videos, although covering the same material as the lectures are not live and are not actually filmed in the lecture theatre but in a studio. They are specifically designed and produced to meet the teaching and learning needs of students.

Each video is segmented into learning modules of about 15 minutes each, which means that a student can watch all or just a particular section of the video or can view it all, but in discrete 'chunks'. The format of the videos is that theory is covered, relevant problems are worked together as part of the video and then the students take a break and work through individual problems. This "hands-on", learning by doing approach is one that is very popular with students since it is in tune with the way students learn best. It is also in tune with the ethos of RMIT University as an institution producing practically focused, work ready graduates, as previously discussed.

Videos, which have now been produced for use in conjunction with several different lecture and laboratory classes, are accessed via Blackboard, which is part of RMIT's Learning Hub. They are thus a practical and readily accessible learning tool as well as an innovative one.

Since these videos are comprehensive in their coverage and segmented into appropriate learning "chunks" which makes their presentation clear and logical, it is possible for students to skip class and merely use the video material. The author has found, however, that this does not generally occur. The videos alone may be used on occasions, as is their intent, when a class is missed, but generally they are used as a supplement to rather than a substitute for lectures.

It is because of the format and the quality of the end product that the videos achieve a number of significant objectives/benefits:

- Enable students to review lecture material over and over again;

- Enable a student who has missed a lecture to catch up easily;

- Provide an additional resource and significant assistance to international students whose language skills may still require honing;

- Present opportunities for use in distance education;

- Satisfy the demand of students for visual rather than written course material; 
- Assist in the transition from secondary to tertiary studies;

- Assist students to address any special learning needs;

- Provide for uniform quality and consistency across lab sections of courses;

- Contribute significantly to student retention;

- Provide marketing opportunities;

- Provide opportunities for off-shore delivery.

- Allow maximum flexibility by being available on RMIT's Learning Hub as well as available to download and view at home or elsewhere.

Solicited and unsolicited student feedback is extremely positive with requests for similar material to be developed for other courses. Although this approach is by no means universally employed within engineering disciplines at RMIT, the author has worked with other lecturers within the School of Electronic and Computer Engineering at the request of the Head of School, to assist them in developing similar material. In addition, building on the success of this approach for first year lecture classes and in an effort to overcome many of the problems associated with laboratory instruction, the author set out last year to undertake a pilot project to see if quasi interactive video could also be introduced to aid student learning in the traditionally challenging area of laboratory teaching. The continued success of quasi interactive video has also prompted development for promotional and other purposes.

RMIT has a Teaching and Learning Group, which focuses on development of on-line material and general teaching aids, and feedback from this Group has been very positive. Comments from colleagues both at RMIT and other Australian institutions have also been extremely positive about the value of quasi interactive video material as a teaching tool and about its potential for use in other arenas. Dr. Peter O'Shea at the Queensland University of Technology is also producing video material with very positive results.

The author has won two awards in 2006 for teaching large classes. The RMIT Certificate of Achievement 2006 University Teaching Award - Teaching Large Classes and Science, Engineering and Technology Portfolio Teaching Award - First Year, Large Class Teaching.

Although feedback from colleagues is very important, the author considers student feedback to be the most important. After the first complete academic year of using the video material in Electronics 1, a survey was undertaken of all students enrolled in the subject. $87 \%$ of students rated the videos as being effective as a teaching tool, with $62 \%$ of this number considering them to be very effective. In response to a question about the use of videos in other courses, $98 \%$ of students were in favour of this. In the second semester of 2005 survey, $94 \%$ of students enrolled indicated that the videos were effective in explaining the subject matter with $70 \%$ of this number considering them to be very effective. $92 \%$ of students surveyed wanted to see videos introduced into other courses. In the second semester of 2006 survey for the new design course $100 \%$ of students enrolled indicated that the videos were effective in explaining the subject matter with $74.5 \%$ of this number considering them to be very effective.

Students' comments throughout each academic year had also been very encouraging but it was valuable to have this confirmed by survey results.

The only real negative comment received from students about this work related to the difficulties they experienced from time to time in accessing the material via Blackboard and the fact that the videos could not be viewed from home without Broadband. There were a 
number of hurdles to overcome in making the video material available in alternative formats but in response to student concerns, the videos are now available on CD.

In addition to specific localized surveys referred to above, RMIT undertakes a more comprehensive and generalized survey each semester, which relates to the course experience of students. No quantitative data is available from this to support the video work because the survey is not able to be that specific. However, the survey also provides an opportunity for comments and students have taken advantage of this opportunity in large numbers to voice their support of quasi interactive videos as a valuable supplementary learning aid, particularly in first year.

In terms of student grades, there are many variables which make it hard to actually quantify but overall performance in Electronics 1 has improved over the last three course offerings, with over $50 \%$ of students achieving a grade of A or B in 2004 as compared to $35 \%-40 \%$ achieving the same grades prior to the introduction of the videos.

It is difficult to determine the extent to which this practice influences exam results but it is fair to say that the majority of students have a positive perception of the class, have a sound practical understanding of the material being taught and move on to the next phase of their program well prepared and confident.

\section{Conclusion}

Large first year engineering classes are a way of life at RMIT University and hopefully are here to stay, because if not, the viability of programs is under threat. Meeting the challenges presented by such large classes is therefore an ongoing reality. Qualitative survey data indicates that the seven elements above are critical factors in responding successfully to this challenge, but the practical focus and nature of programs and the availability of quasi interactive videos continue to emerge as the most influential and critical success factors.

\section{References}

1. Schreyer Institute for Teaching Excellence "Large Classes versus Small: Does It Make a Difference?"

2. Islam R. "Reflections on Large Class Teaching "- Charles Sturt University.

3. Light, P. \& V. Light (1999) “Analysing asynchronous learning interactions: Computer mediated communication in a conventional undergraduate setting, in K. Littleton \& P. Light (Eds) Learning with Computers: Analysing productive interactions (London, Routledge), 162-178

4. "Quasi Interactive Video Production as a Teaching, Marketing and Retention Tool”, Proceedings of the 2005 American Society for Engineering Annual Conference and Exposition, Portland, Oregon.

5. "Quasi Interactive Video: An Innovative Approach to the Delivery of Laboratory Courses", Proceedings of the 2006 American Society for Engineering Annual Conference and Exposition, Chicago, Illinois 